\title{
Dual Use of an Arterio-Venous Fistula for Total Parentral Nutrition and Haemodialysis: Potential and Pitfalls
}

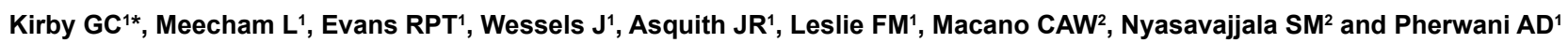

${ }^{1}$ Department of Vascular Surgery, Royal Stoke University Hospital, Newcastle Road, UK

${ }^{2}$ Heart of England NHS Foundation Trust, UK

\begin{abstract}
Introduction: We present the dual use of an arteriovenous fistula (AVF) for contemporaneous administration of home parenteral nutrition (PN), and hemodialysis (HD).

Case Report: A 52 year old female patient required PN due to short bowel syndrome, following extensive resection for ischemic bowel. After she was rendered dialysis dependent secondary to multifactorial renal failure, a left forearm basilica vein transposition onto the radial artery was undertaken. Venous access for PN was problematic. We commenced home PN via the AVF, using a 'buttonhole' technique to cannulate the fistula for both HD and PN.

The peripheral administration of PN necessitated reduction in the osmolality, with larger volumes and longer administration times. This required adjustment of the HD regime to compensate. The patient received simultaneous PN and HD at home through the AVF successfully for seven weeks. Unfortunately after this time she suffered a staphylococcal fistula infection with septicemia.

Discussion: We have shown that dual use of AVF for HD and PN is feasible, although not without risk. Reduction of osmolality and staggering of $\mathrm{PN}$ and $\mathrm{HD}$ sessions is required, with administration of PN over longer times. It has been shown that the buttonhole cannulation technique has a higher rate of infection than alternatives, and we propose this may have contributed to our patient's complication. We believe this report would be helpful if dual use of AVF for $\mathrm{PN}$ and HD is contemplated.
\end{abstract}

Keywords: Arterio-venous fistula; Hemodialysis; Home parenteral nutrition

\section{Introduction}

Long term home parenteral nutrition (HPN), is an integral part of the management of intestinal failure, for disorders such as short bowel syndrome, and inflammatory bowel disease [1,2]. Venous access for these patients is vital for their care, but can prove problematic. There is limited discussion in the literature of utilisation of surgically created arteriovenous fistulae (AVF) for therapies other than hemodialysis (HD). However it has been shown to be feasible to administer HPN via this route $[3,4]$.

A small study has observed the infection rates for AVF used for parenteral nutrition to be lower than that for central venous catheters, with slightly higher occlusion rates [5]. Whilst there is very limited experience of dual use of an AVF for concurrent parenteral nutrition (PN) and HD in the literature, a case series of three patients has shown successful application of HD and HPN via AVF, without complication, for between one and twenty months [6].

We aim to assess the potential of using AVF for HPN and HD. We report our experiences, and in particular techniques we used and lessons learnt which could help clinicians considering this technique for their patients in the future, illustrated by a case report.

\section{Case Report}

We present the case of a 52 year old female, who required HPN and concurrent home HD. Having suffered acute bowel ischemia, she underwent extensive small bowel resection and right hemicolectomy seven years prior to presentation, leaving her with $110 \mathrm{~cm}$ of small bowel, an ileostomy and mucus fistula. She was initially dependent on fluid and magnesium infusions, and subsequently required HPN.

The aetiology of renal failure was multifactorial. She had right sided renovascular disease and renal artery thrombosis, and duplex left collecting system. She underwent left nephrostomy insertion for presumed distal obstruction, which was complicated by bleeding requiring renal angiogram and embolization of the lower pole of the kidney, resulting in further decline in her renal function.

Rendered end stage and dialysis dependent, she received HD initially via left internal jugular vein Terumo catheter, and subsequently left forearm arteriovenous fistula. We performed left forearm basilic vein transposition on to the radial artery. This was accessed for HD using a buttonhole technique, for six months.

Venous access for electrolyte replacement and PN was carried out through right internal jugular vein tunnelled Hickman line. After failure of the catheter due to line fracture, there was much discussion about the best route for access. Reinsertion in the neck was avoided due to right internal jugular vein stenosis and left innominate vein narrowing, as a result of the previous lines, including the initial tunnelled HD catheters.

PN via the AVF was introduced as an inpatient. Buttonholes were maintained for $\mathrm{HD}$, and a new buttonhole was created for

*Corresponding author: Kirby GC, Department of Vascular Surgery, Royal Stoke University Hospital, Newcastle Road, Stoke-on-Trent, UK, Tel: 447973939753 E-mail: kirbyg@doctors.net.uk

Received January 31, 2017; Accepted February 16, 2017; Published February 26, 2017

Citation: Kirby GC, Meecham L, Evans RPT, Wessels J, Asquith JR, et al. (2017) Dual Use of an Arterio-Venous Fistula for Total Parentral Nutrition and Haemodialysis: Potential and Pitfalls. Med Rep Case Stud 2: 128. doi: 10.4172/2572-5130.1000128

Copyright: @ 2017 Kirby GC, et al. This is an open-access article distributed unde the terms of the Creative Commons Attribution License, which permits unrestricted use, distribution, and reproduction in any medium, provided the original author and source are credited. 
Citation: Kirby GC, Meecham L, Evans RPT, Wessels J, Asquith JR, et al. (2017) Dual Use of an Arterio-Venous Fistula for Total Parentral Nutrition and Haemodialysis: Potential and Pitfalls. Med Rep Case Stud 2: 128. doi: 10.4172/2572-5130.1000128

Page 2 of 2

administration of HPN. Standard care of the buttonholes included cleaning with chlorhexidine, and use of chlorhexidine dressings.

It is recommended that the osmolality of $\mathrm{PN}$ is reduced when given peripherally, to reduce the incidence of thrombophlebitis [7,8]. In our institution the PN used in provided by Fresenius Kabi Ltd, Runcorn, UK. Following the manufacturer recommendations for parenteral nutrition, the osmolality was reduced from $1100 \mathrm{mOSm} / 1$ to 930 $\mathrm{mOsm} / \mathrm{L}$. This required the reduction in calories from carbohydrate, and the increase in volume from the usual regime of 1.5 litres to 2.2 litres. The increased volume required a longer administration time of 16 hours per infusion.

The feeding and dialysis regimes were designed to not coincide, preventing loss of nutritional value. $\mathrm{PN}$ was administered five times a week: twice nocturnally and three times during the day, with haemodialysis four times a week, for three and a half hours. A siliconized vascular access catheter (Nipro Medical Europe, Belgium) was used, as the soft nature is both more comfortable for the patient, and reduces the risk of inadvertent injury to the fistula during nocturnal use.

During this time the patient had a fluid restriction of one litre orally in 24 hours. HD was recalibrated to dialyse off the additional volume of PN. HD was performed using a FX100 dialyser with a Fresenius 5008 machine. After seven weeks unfortunately $\mathrm{HD}$ and peripheral $\mathrm{PN}$ was complicated by a fistula infection, with staphylococcus septicaemia and metastatic pulmonary deposits which was managed with intravenous antibiotics, and surgical refashioning of the fistula.

Subsequently PN was recommenced via a temporary groin line, and the AVF was used for HD. Thereafter venoplasty of the stenosed right internal jugular vein allowed further central venous catheter placement for ongoing $\mathrm{PN}$.

Currently the patient is being worked up for renal transplant, and restoration of bowel continuity. The original left forearm AVF continues to function well for HD.

\section{Discussion}

We have proven contemporaneous administration of $\mathrm{PN}$ and $\mathrm{HD}$ via AVF is feasible, and in patients who do not have alternative venous access may be provide a useful extra route for patients with renal and intestinal failure. Additional considerations for utilization of an AVF in this manner are the reduction in osmolality of parenteral nutrition to allow peripheral administration, timing of HD and HPN, and the use of a siliconised catheter for nocturnal use. Dual use of AVF is not without risk. Our case demonstrates the potential for infection of the fistula. In retrospect the likely causative factor in the fistula infection was use of a 'buttonhole' technique for administration of the PN. It has been suggested that there is an increased risk of infective complications using this cannulation method [9]. We would suggest use of a 'rope ladder' technique for future delivery.

\section{References}

1. Jeppesen PB (2014) Spectrum of short bowel syndrome in adults: intestinal insufficiency to intestinal failure. J Parenter Enteral Nutr 38: 8S-13S.

2. Storch KJ (2014) Overview of short bowel syndrome: clinical features pathophysiology, impact, and management. J Parenter Enteral Nutr 38: 5S-7S

3. Versleijen M, Vissers R, Wanten G (2008) Excellent quality of life after 31 years of parenteral nutrition via an arteriovenous fistula. Eur J Clin Nutr 62: 1253-1254.

4. Carsten III CG, Taylor SM, Cull DL, Langan III EM, Snyder BA, et al. (2004) The surgically created arteriovenous fistula: a forgotten alternative to venous access. Ann Vasc Surg 18: 635-639.

5. Versleijen MW, Huisman-de Waal GJ, Kock MC, Elferink AJ, van Rossum LG, et al. (2009) Arteriovenous fistulae as an alternative to central venous catheters for delivery of long-term home parenteral nutrition. Gastroenterology 136: $1577-1584$.

6. Tang VCY, Morsy MA, Chemla ES (2007) Using arteriovenous fistulae as a dual access for hemodialysis and total parenteral nutrition administration is feasible with a good outcome: a case series. J Vas Acc 8: 305-308.

7. Boullata JI, Gilbert K, Sacks G, Labossiere RJ, Crill C, et al. (2014) ASPEN Clinical Guidelines: Parenteral Nutrition Ordering, Order Review, Compounding, Labeling, and Dispensing. J Parenter Enter Nutr 38: 334-377.

8. Pittiruti $M$, Hamilton $H$, Biffi $R$, MacFie J, Pertkiewicz $M$ (2009) ESPEN Guidelines on Parenteral Nutrition: central venous catheters (access, care, diagnosis and therapy of complications). Clin Nutr 28: 365-377.

9. Labriola L, Crott R, Desmet C, André G, Jadoul M (2011) Infectious complications following conversion to buttonhole cannulation of native arteriovenous fistulas: a quality improvement report. Am J Kidney Dis 57: 442-448. 